\title{
Impact Resistance and Sodium Sulphate Attack Testing of Concrete Incorporating Mixed Types of Recycled Plastic Waste
}

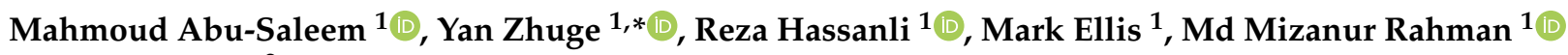 \\ and Peter Levett ${ }^{2}$ \\ 1 UniSA STEM, Scarce Resources and Circular Economy (ScaRCE), University of South Australia, \\ Adelaide, SA 5000, Australia; mahmoud_ahmad_mahmoud.abu_saleem@mymail.unisa.edu.au (M.A.-S.); \\ Reza.Hassanli@unisa.edu.au (R.H.); Mark.Ellis@unisa.edu.au (M.E.); \\ Mizanur.Rahman@unisa.edu.au (M.M.R.) \\ 2 Salisbury City Council, City of Salisbury, Salisbury, SA 5108, Australia; PLevett@salisbury.sa.gov.au \\ * Correspondence: Yan.Zhuge@unisa.edu.au
}

check for updates

Citation: Abu-Saleem, M.; Zhuge, Y.; Hassanli, R.; Ellis, M.; Rahman, M.M.; Levett, P. Impact Resistance and Sodium Sulphate Attack Testing of Concrete Incorporating Mixed Types of Recycled Plastic Waste. Sustainability 2021, 13, 9521. https:// doi.org/10.3390/su13179521

Academic Editor: Syed Minhaj Saleem Kazmi

Received: 20 July 2021

Accepted: 21 August 2021

Published: 24 August 2021

Publisher's Note: MDPI stays neutral with regard to jurisdictional claims in published maps and institutional affiliations.

Copyright: (c) 2021 by the authors. Licensee MDPI, Basel, Switzerland. This article is an open access article distributed under the terms and conditions of the Creative Commons Attribution (CC BY) license (https:// creativecommons.org/licenses/by/ $4.0 /)$.

\begin{abstract}
Impact resistance, water transport properties and sodium sulphate attack are important criteria to determine the performance of concrete incorporating mixed types of recycled plastic waste. Nine mixes were designed with different combinations of the three plastic types; Polyethylene terephthalate (PET), High density polyethylene (HDPE) and Polypropylene (PP). The plastic partially substituted the coarse aggregate (by volume) at various replacement ratios; $10 \%, 15 \%, 20 \%$ and $30 \%$. The impact resistance and water transport properties were evaluated for nine mixes while sodium sulphate attack test was performed for three mixes. The results showed that the addition of mixed recycled plastic in concrete improved the impact resistance. The highest impact resistance improvement was achieved by R8 (PET + HDPE + PP) at 30\% replacement which was 4.5 times better than the control mix. Water absorption results indicated a slight increase in all plastic mixes while contradictory results were observed for sorptivity test. Analysis of sodium sulphate attack results showed that incorporating 30\% mixed plastic reduced the sodium sulphate resistance slightly due to the collective effect of plastic entrapping of sulphate ions after 80 cycles. This study has shown some positive results relating to the impact performance of Mixed Recycled Plastic Concrete (MRPC) which enhances its use in a sustainable way.
\end{abstract}

Keywords: mixed recycled plastic concrete; impact resistance; water transport properties; sodium sulphate attack; scanning electron microscope (SEM); energy dispersive X-ray analysis (EDS)

\section{Introduction}

The plastic pollution in water and soil is alarming in Australia and local authorities are focusing on expanding plastic recycling in order to mitigate plastic related environmental pollution. The plastic recycling campaign gained more significant interest since 2019 when the Australian Government announced seven targets in the national waste policy action plan [1] —one of which states "Significantly increase the use of recycled content by governments and industry". As the need increased to find a more sustainable and environmentally friendly solution for the accumulated plastic waste that requires little or no further processing, the construction sector was proposed to accommodate part of the plastic waste solution. Since then, the research on the use of waste plastic as aggregate in concrete has attracted widespread attention, and is still in progress. Extensive investigations were carried out to explore the engineering properties of concrete using a specific type of recycled plastic in many countries around the world [2,3]. However, there are still many aspects that need to be addressed, such as the effect of using mixed recycled plastics on the performance of concrete.

One of the main problems facing the recycling plants in Australia is the mixed plastic waste or unsorted plastic types, which is usually diverted to landfill. Contaminants 
and limited screening capacity in recycling facilities result in plastics that are neither mechanically nor chemically recyclable. Immiscibility between different plastic types at the molecular level is one of the main obstacles in chemical recycling. Moreover, the cost of sorting one tonne of mixed plastic ranges from EUR 50-200 (AUD 80-320) [4]. Recently, the growing concern to dispose of this mixed material properly without detrimental effect on the environment encourages more research to be conducted on mixed plastic concrete.

The performance of concrete mixed with one type of plastic is definitely different from that mixed with two or three types and certainly different from concrete incorporating mixed unknown types. This is attributed to the variations of the plastic in their structure, physical and chemical properties. PET, HDPE and PP belong to the thermoplastic group; HDPE and PP are manufactured by the polyaddition process, which means repeating of the same monomer along the chain, while PET is an example of plastics manufactured by condensation $[5,6]$.

Water absorption of concrete is a measure of the amount of water penetrating a concrete specimen while water sorptivity is a measure of the concrete's ability to ab-sorb and transfer water through it by capillary suction. Testing results of water absorption and sorptivity properties provide valuable information in relation to the long-term durability performance of concrete structure. In general, higher porosity resulted in higher water absorption, which in turn lower the durability of concrete. By far, there are only limited studies on water transport properties of MRPC. Jacob-Vaillancourt and Sorelli [7] studied the water absorption of concrete incorporating mixed plastic types (Polyethylene, Polypropylene, Polystyrene, Polyvinyl chloride and others) and reported that the produced concrete exhibited a reduction in water absorption due to the so-called hydrophobic nature of the plastics. Hydrophobicity of plastic is defined as the law affinity towards water. Due to the differences in plastics structure at the molecular level, different types of plastic have different tendency to water. Moreover, Mohammadinia et al. [8] found a decrease in values of sorptivity in specimens contained unknown mixed plastic types up to $30 \%$. To the best knowledge of authors, no information concerning the impact resistance and sodium sulphate attack of MRPC was found in the literature.

The impact resistance property of the concrete mixed with a single type of plastic to partially replace the aggregate was investigated, and some promising observations have been reported. Saxena et al. [9] studied the impact behaviour of concrete including shredded recycled PET bottles with a replacement ratio up to $20 \%$ (by weight) as coarse and fine aggregates. They reported an increase in the number of blows, the energy absorption capacity and an improvement in the ductility behaviour of the yielded concrete. Similarly, Jain et al. [10] found an enhancement in number of blows for final failure of the concrete discs by $392 \%$ when replacing $20 \%$ of waste plastic bags as fine aggregate.

Concrete resistance to sulphate attack is an important parameter in judging the durability of concrete since vulnerable concrete to sulphate ions suffers from expansion and deterioration [11]. Several researchers addressed the sodium sulphate attack property of concrete incorporated a single type of plastic aggregate. Benosman et al. [12] investigated the sodium sulphate attack of mortar containing $6 \%, 12 \%, 17 \%$ of PET plastic waste particles to replace Portland cement. The results showed that, at 180 days, the weight change decreased with increasing the replacement ratio up to $12 \%$.

A research program has been undertaken by the authors of this paper to study the effect of mixing three plastic types; (PET, HDPE and PP) in different combinations and replacement ratios on the concrete properties. The physical and mechanical properties of concrete incorporating mixed types of recycled plastic waste were studied previously [13]. Hence, this paper aims to investigate the impact resistance, water transport properties and sodium sulphate attack of MRPC to clearly understand these durability concerns and to ensure the sustainability of this type of concrete if a decision is made to use it in practical applications. The tested properties of the concrete took into account two main variables, (1) different combinations of three mixed types of recycled plastic and (2) varying replacement ratios. The results could provide useful information on the impact resistance 
and durability of mixed recycled plastic concrete, promoting its uses in a sustainable way to convert the waste into valuable environmentally friendly resources.

Although the mix design developed for this research was based on kerb construction, it could be applied to low to medium traffic volume roads, such as parking lots and residential streets. Sustainable utilisation of plastic wastes in pavement construction could offer a long-term environmental benefit. Currently, the potential application of concrete containing mixed types of recycled plastic aggregates as a replacement of natural aggregate in residential pavement applications is one of the most encouraging ideas to accommodate significant amounts of the recycled plastic; for example, the City of Salisbury, South Australia has $760 \mathrm{~km}$ of residential roads. However, the impact resistance and durability performance of concrete with unsorted recycled plastics have been a concern for pavement use, but neither a conclusive nor satisfactory answer is available in the literature. Since a low impact resistance and durability characteristics can lead to a reduction in performance and pavement life, an investigation with a systematic variation of unsorted recycled plastics will provide answers along with recommendations for the interested parties who intend to start using concrete containing mixed plastic types for pavement application.

\section{Experimental Program}

\subsection{Materials}

Three types of shredded recycled plastic waste aggregates-PET, HDPE and PP-were used in this study; the colour and appearance of the plastics can be found in authors previous publication [13]. Table 1 briefly describes some features of the three types of plastic. General purpose (GP) cement (specific gravity 3.15) was used as a binder material for all mixes. The coarse and fine aggregates employed in this study were sourced from Jennings Rosedale and Rocla Golden Grove, Australia, respectively. The particle density, apparent particle density and water absorption for coarse and fine aggregate were measured according to AS 1141.6.1 [14] and AS 1141.5 [15], respectively, as shown in Table 2.

Table 1. Properties of the three plastic types (PET, HDPE and PP).

\begin{tabular}{cccc}
\hline Property & PET & PP \\
\hline Chemical formula & {$\left[\mathrm{C}_{10} \mathrm{H}_{8} \mathrm{O}_{4}\right]_{\mathrm{n}}$} \\
Repeating unit & ethylene terephthalate & {$\left[\mathrm{CH}_{\left.\left(-\mathrm{CH}_{3}\right) \mathrm{CH}_{2}\right]_{\mathrm{n}}}\right.$} \\
Saturation & unsaturated polymer & saturated polymer & saturated polymer \\
\hline
\end{tabular}

Table 2. Physical properties of natural and plastic aggregates.

\begin{tabular}{|c|c|c|c|c|c|c|}
\hline \multicolumn{2}{|c|}{ Aggregate } & $\begin{array}{c}\text { Particle Density } \\
\text { on a Saturated } \\
\text { Surface-Dried }\left(\mathrm{t} / \mathrm{m}^{3}\right) \\
\text { (AS Code) }\end{array}$ & $\begin{array}{c}\text { Apparent } \\
\text { Particle Density }\left(\mathrm{t} / \mathrm{m}^{3}\right) \\
\text { (AS Code) }\end{array}$ & $\begin{array}{c}\text { Water } \\
\text { Absorption (\%) } \\
\text { (AS Code) }\end{array}$ & $\begin{array}{c}\text { Specific } \\
\text { Gravity } \\
\text { (ASTM Code) }\end{array}$ & $\begin{array}{c}\begin{array}{c}\text { Density } \\
\left(\mathrm{kg} / \mathrm{m}^{3}\right)\end{array} \\
\text { (ASTM Code) }\end{array}$ \\
\hline \multirow{4}{*}{ Coarse } & Stone & 2.73 & 2.83 & 2.3 & - & - \\
\hline & PET & - & - & - & 1.23 & 1224.95 \\
\hline & HDPE & - & - & - & 0.96 & 960.48 \\
\hline & PP & - & - & - & 0.91 & 905.32 \\
\hline \multicolumn{2}{|c|}{ Fine } & 2.6 & 2.61 & 0.17 & - & - \\
\hline
\end{tabular}


Direct mix design was followed to prepare the mixes, which means that the plastic was used in the condition in which it was received, i.e., without any treatment or washing. The specific gravity and density of PET, HDPE and PP were measured according to ASTM D792 [16] as shown in Table 2.

MasterGlenium superplasticizer SKY 8708 with a specific gravity of 1.085 was used to obtain a slump value more than $80 \mathrm{~mm}$. Particle size distribution for natural and shredded recycled plastic waste aggregates were carried out in accordance with AS 1141.11.1 [17] and shown in a previous study [13]. Figure 2 in [13] showed the maximum size for the natural coarse and fine aggregates were $14 \mathrm{~mm}$ and $4.75 \mathrm{~mm}$, respectively. Four different types of mixed recycled plastic waste have a maximum particle size of $13.2 \mathrm{~mm}$ and were used as a partial replacement of coarse aggregate by volume.

\subsection{Mix Design and Specimens Preparation}

Nine different combinations of the three types of plastic partially replaced the coarse aggregate by volume (Table 3) [13]. AS 1012.2 [18] was followed for the manufacturing process of the mixes. Specimens were demoulded after $24 \mathrm{~h}$ of casting and water cured at $23 \pm 2{ }^{\circ} \mathrm{C}$ according to AS 1012.8.1 [19] until the specific age of testing. A total of 63 cylinders (diameter: $100 \mathrm{~mm} \times$ height: $200 \mathrm{~mm}$ ) were prepared for water transport properties and sodium sulphate attack tests. Eighteen cylinders (diameter: $150 \mathrm{~mm} \times$ height: $300 \mathrm{~mm}$ with two $25 \mathrm{~mm}$ triangular notches) were prepared for impact resistance test. Table 4 summarizes the tests conducted and the number of specimens for each mix.

Table 3. Detailed mix proportion of all mixes [13].

\begin{tabular}{|c|c|c|c|c|c|c|c|c|c|c|}
\hline \multirow{3}{*}{ Mix } & \multirow{3}{*}{ Mix ID } & \multirow{3}{*}{$\operatorname{Rc}(\%)^{1}$} & \multicolumn{8}{|c|}{ Mix Quantities $\left(\mathrm{kg} / \mathrm{m}^{3}\right)$} \\
\hline & & & \multirow{2}{*}{ Cement } & \multirow{2}{*}{ Water } & \multirow{2}{*}{ Fine } & \multirow{2}{*}{ Coarse } & \multicolumn{3}{|c|}{ Plastic } & \multirow{2}{*}{$\mathrm{SP}^{2}$} \\
\hline & & & & & & & PET & HDPE & PP & \\
\hline Control & control & - & 320.2 & 241.5 & 886.3 & 858.5 & - & - & - & 1.8 \\
\hline PET5\% + HDPE5\% & $\mathrm{R} 1$ & 10 & 320.2 & 241.5 & 886.3 & 772.65 & 19.34 & 15.10 & - & 1.8 \\
\hline PET10\% + HDPE10\% & $\mathrm{R} 2$ & 20 & 320.2 & 241.5 & 886.3 & 686.8 & 38.68 & 30.19 & - & 1.8 \\
\hline PET5\% + PP5\% & R3 & 10 & 320.2 & 241.5 & 886.3 & 772.65 & 19.34 & - & 14.31 & 1.8 \\
\hline PET10\% + PP10\% & $\mathrm{R} 4$ & 20 & 320.2 & 241.5 & 886.3 & 686.8 & 38.68 & - & 28.61 & 1.8 \\
\hline HDPE5\% + PP5\% & $\mathrm{R} 5$ & 10 & 320.2 & 241.5 & 886.3 & 772.65 & - & 15.10 & 14.31 & 1.8 \\
\hline HDPE10\% + PP10\% & R6 & 20 & 320.2 & 241.5 & 886.3 & 686.8 & - & 30.19 & 28.61 & 1.8 \\
\hline PET5\% + HDPE5\% + PP5\% & R7 & 15 & 320.2 & 241.5 & 886.3 & 729.73 & 19.34 & 15.10 & 14.31 & 1.8 \\
\hline PET10\% + HDPE10\% + PP10\% & $\mathrm{R} 8$ & 30 & 320.2 & 241.5 & 886.3 & 600.95 & 38.68 & 30.19 & 28.61 & 1.8 \\
\hline
\end{tabular}

${ }^{1}$ Rc: Percentage of coarse aggregate replaced by plastic (by volume). ${ }^{2}$ SP: Superplasticizer.

Table 4. Summary of tests and number of specimens.

\begin{tabular}{|c|c|c|c|c|c|c|c|c|}
\hline \multirow{3}{*}{ Mix ID } & \multicolumn{4}{|c|}{ Conducted Tests } & \multicolumn{4}{|c|}{ Number of Specimens } \\
\hline & \multirow{2}{*}{$\begin{array}{c}\text { Impact } \\
\text { Resistance }\end{array}$} & \multicolumn{2}{|c|}{$\begin{array}{l}\text { Water Transport } \\
\text { Properties }\end{array}$} & \multirow{2}{*}{$\begin{array}{l}\text { Sodium } \\
\text { Sulphate } \\
\text { Attack }\end{array}$} & \multirow{2}{*}{$\begin{array}{c}\text { Impact } \\
\text { Resistance }\end{array}$} & \multicolumn{2}{|c|}{$\begin{array}{l}\text { Water Transport } \\
\text { Properties }\end{array}$} & \multirow{2}{*}{$\begin{array}{c}\text { Sodium } \\
\text { Sulphate } \\
\text { Attack }\end{array}$} \\
\hline & & $\begin{array}{c}\text { Water } \\
\text { Absorption }\end{array}$ & $\begin{array}{c}\text { Water } \\
\text { Sorptivity }\end{array}$ & & & $\begin{array}{c}\text { Water } \\
\text { Absorption }\end{array}$ & $\begin{array}{c}\text { Water } \\
\text { Sorptivity }\end{array}$ & \\
\hline control & $\checkmark$ & $\checkmark$ & $\checkmark$ & $\checkmark$ & 10 discs & 9 discs & 6 discs & 3 cylinders \\
\hline $\mathrm{R} 1$ & $\checkmark$ & $\checkmark$ & $\checkmark$ & - & 10 discs & 9 discs & 6 discs & - \\
\hline $\mathrm{R} 2$ & $\checkmark$ & $\checkmark$ & $\checkmark$ & - & 10 discs & 9 discs & 6 discs & - \\
\hline $\mathrm{R} 3$ & $\checkmark$ & $\checkmark$ & $\checkmark$ & - & 10 discs & 9 discs & 6 discs & - \\
\hline $\mathrm{R} 4$ & $\checkmark$ & $\checkmark$ & $\checkmark$ & - & 10 discs & 9 discs & 6 discs & - \\
\hline $\mathrm{R} 5$ & $\checkmark$ & $\checkmark$ & $\checkmark$ & - & 10 discs & 9 discs & 6 discs & - \\
\hline R6 & $\checkmark$ & $\checkmark$ & $\checkmark$ & - & 10 discs & 9 discs & 6 discs & - \\
\hline R7 & $\checkmark$ & $\checkmark$ & $\checkmark$ & $\checkmark$ & 10 discs & 9 discs & 6 discs & 3 cylinders \\
\hline $\mathrm{R} 8$ & $\checkmark$ & $\checkmark$ & $\checkmark$ & $\checkmark$ & 10 discs & 9 discs & 6 discs & 3 cylinders \\
\hline
\end{tabular}




\subsection{Hardened Concrete Tests}

\subsubsection{Impact Resistance Test}

The impact strength of concrete is the capability of concrete to tolerate repeated blows and to absorb energy. It is necessary to measure the impact strength of MRPC to predict future performance for practical applications. The impact resistance test was performed according to ACI 544 [20] by using a drop weight method. Figure 1 shows the impact test apparatus. The test was carried out by repeatedly dropping a $4.5 \mathrm{~kg}$ steel cylinder (diameter: $65.8 \mathrm{~mm} \times$ height: $162.3 \mathrm{~mm}$ ) along a smooth steel tube with an internal diameter of $67 \mathrm{~mm}$ from a columnar height of $200 \mathrm{~mm}$ onto a steel ball. The height was adjusted to be $200 \mathrm{~mm}$ to suit the current concrete strength. The weight of the steel ball was $1.045 \mathrm{~kg}$ and it was placed in the centre of the concrete disc top surface that positioned on a horizontal steel base. The design of the concrete disc was proposed by [21], where each disc has a $150 \mathrm{~mm}$ diameter with a thickness of $50 \mathrm{~mm}$ and two $25 \mathrm{~mm}$ triangular notches located at the ends of the specimen diameter. The steel cylinder was repeatedly dropped until the concrete disc fractured completely and that represented the ultimate impact resistance.

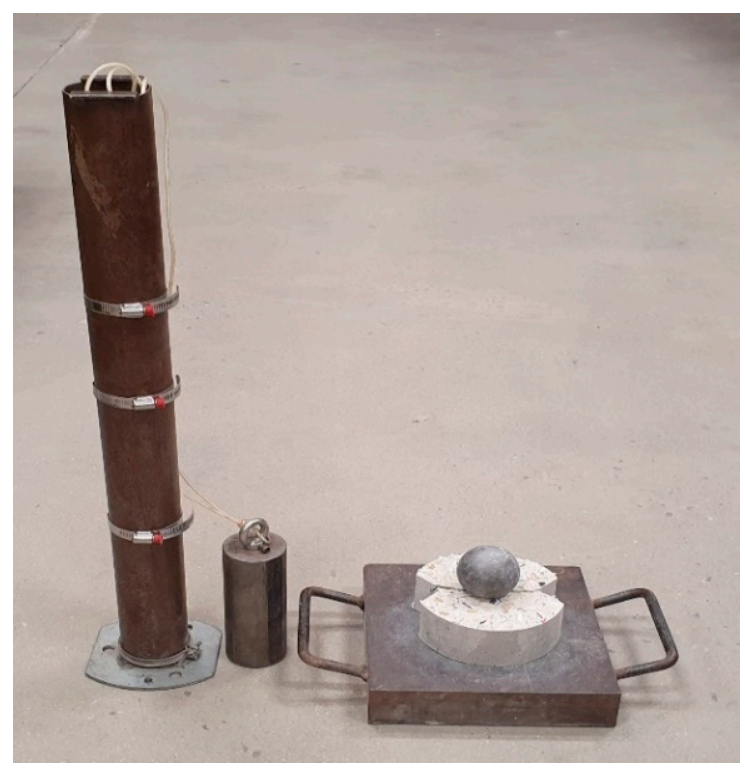

Figure 1. Impact resistance test set up.

\subsubsection{Water Transport Properties}

The water transport properties provide useful information on the rate that water (and any dissolved salts) absorbs in the tested specimens. Water absorption test setup was in accordance with AS 1012.21 [22]. Three samples from each mix were taken to test after 28 days curing. The test was conducted by immersing oven dried samples with a $100 \mathrm{~mm}$ diameter, $50 \mathrm{~mm}$ thick discs, cutting from the $200 \mathrm{~mm}$ long cylinders, in water at $23 \pm 2{ }^{\circ} \mathrm{C}$. The drying process was done by placing the discs in an oven at $105^{\circ} \mathrm{C}$ for 3 days. The discs were then left to cool to the room temperature of $\left(23 \pm 2{ }^{\circ} \mathrm{C}\right)$ before being immersed in water for 3 days. The water absorption value was calculated by Equation (1).

$$
\text { Water absorption }(\%)=\frac{\left(m_{2}-m_{1}\right)}{m_{1}} \times 100
$$

$m_{1}$ : The mass of dried disc and $m_{2}$ : The mass of immersed surface dried disc.

Sorptivity is known as the penetration of liquid into porous matrix under unsaturated conditions associated with capillary suction. The water sorptivity test of all mixes was conducted according to ASTM C1585 [23]. Samples of $50 \mathrm{~mm}$ thick disc, cutting from the $200 \mathrm{~mm}$ long $100 \mathrm{~mm}$ diameter cylinders, were placed on supports and immersed in the water pan for up to $1-3 \mathrm{~mm}$ of the concrete bottom surface (above the top of the 
support device). The new weights of the specimens were recorded after 1, 5, 10, 20, 30, 60, 120, 180, 240, 300 and $360 \mathrm{~min}$ then after 1, 2, 3, 5, 6, 7 and 8 days. The water sorptivity coefficients $(\mathrm{mm} / \sqrt{s})$ (initial and secondary rate of absorption) were then determined by linear regression for first 6 hours and the 1st to 8th days, respectively by using Equation (2).

$$
\mathrm{I}=S \sqrt{t}+b
$$

I: the cumulative volume of absorbed water per unit of surface in $\mathrm{mm}^{3} / \mathrm{mm}^{2}$; $S$ : the sorptivity coefficient in $\mathrm{mm} / \sqrt{s}$; $t$ : denotes the time measured in second; $b$ : the constant which reflects effect of initial water filling at concrete surface.

\subsubsection{Sodium Sulphate Attack Test}

The sodium sulphate attack test was carried out for three mixes: control, R7, and R8 according to AS/NZS 4456.10 [24], to compare the effect of two replacement ratios of MRPC. The results were determined by measuring the changes in the mass of concrete cylinders. The test was done in a cyclic pattern; each cycle started by immersing the concrete cylinder in the sodium sulphate solution $\left(\mathrm{Na}_{2} \mathrm{SO}_{4}\right)$ (Figure 2$)$ for 2 hours and finished by taking the weight of the cooled concrete cylinder after drying it in an oven at $65 \pm 2{ }^{\circ} \mathrm{C}$ for $20 \pm 1 \mathrm{~h}$. $\mathrm{Na}_{2} \mathrm{SO}_{4}$ solution was prepared by dissolving $62 \mathrm{~g}$ in $1 \mathrm{~L}$ of potable water. The mass was taken after cooling the cylinders to room temperature within $3 \pm 0.5 \mathrm{~h}$. The solution was changed every week. The changing of the mass was determined by using Equation (3).

$$
\text { The mass change }=\frac{\left(m_{0}-m_{i}\right)}{m_{0}} \times 100
$$

$m_{0}$ : Initial mass of the concrete cylinder; $m_{i}$ : Mass of the concrete cylinder that obtained at the end of each cycle.

The compressive and splitting tensile tests were carried out for the three mixes after 90 dry-wet cycles of exposure. Scanning Electron Microscopy (SEM) and Energy Dispersive $\mathrm{X}$-ray Spectroscopy (EDS) analysis were conducted on selected concrete fractures of the three mixes to have more insight details and identify the products formed by sulphate ions attack.

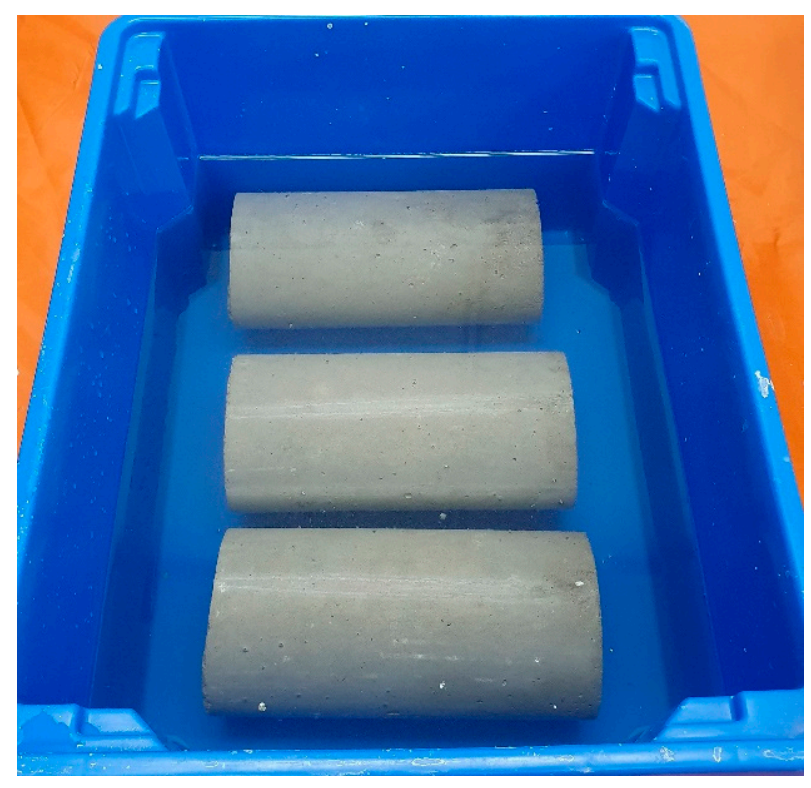

Figure 2. The sodium sulphate attack test. 


\section{Results and Discussion}

\subsection{Impact Resistance}

The impact resistance was assessed in terms of the average number of blows. The findings of the impact test for all MRPC mixes are illustrated in Figure 3. Interestingly, the average number of blows enhanced as the plastic content increased.

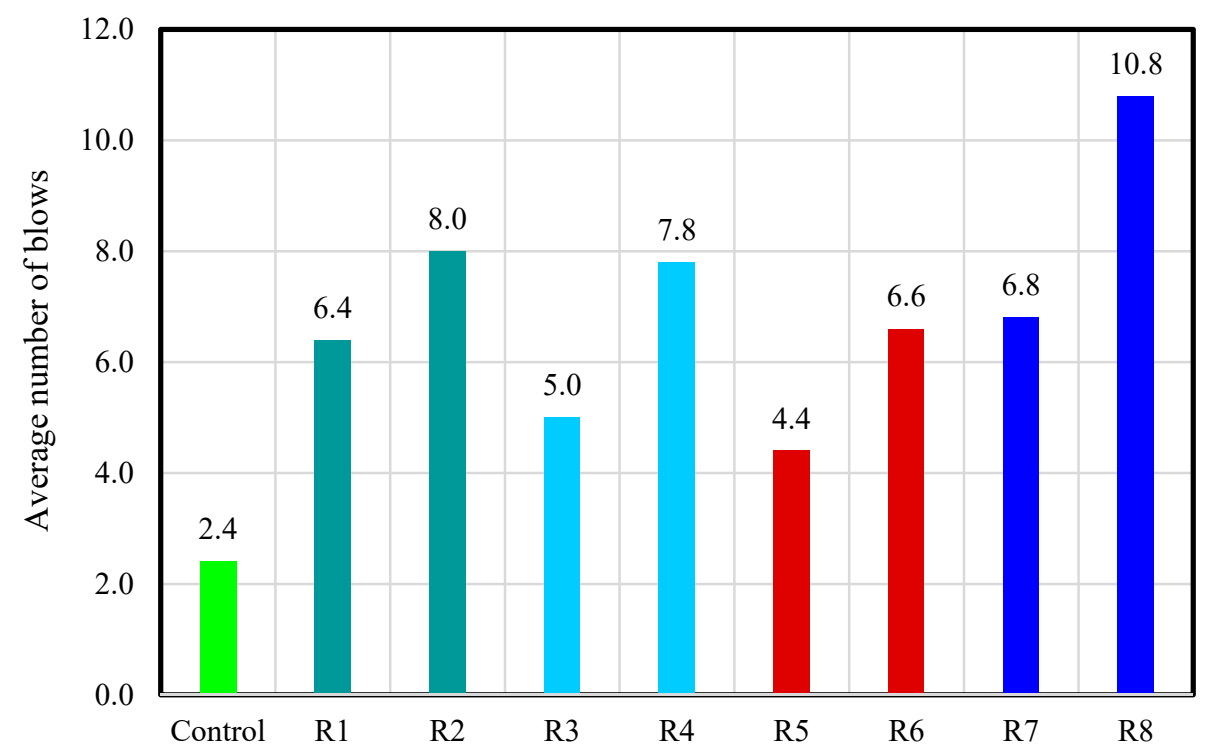

Figure 3. Average number of blows for the different replacement ratios.

Incorporating $10 \%$ mixed recycled plastic aggregate improved the impact strength of R1, R3 and R5 by 2.6, 2.1 and 1.8 times while using 20\% plastic aggregate improved it for R2, R4 and R6 by 3.3, 3.25, 2.75 times compared to the control mix. Comparing the mixes with two plastic types at $10 \%$ and $20 \%$ replacement, R1 and R2 achieved the highest values of ultimate impact strength. The best impact improvement was achieved by R 8 with $30 \%$ plastic aggregate replacement, with 4.5 times higher than the control mix. Furthermore, it should be noted that the improvement of impact resistance in this research compared well with previous findings where a single plastic type was used to partially replace aggregate in concrete [10,25]. Saxena et al. [9] explained that the addition of PET plastic waste aggregate to concrete enhanced the resistance to impact loading as a result of the flexibility and higher elastic properties of the plastic.

The good resistance to impact load of MRPC could be related to two factors; the matrix strength between the plastic aggregate and other constituents and the ability of plastic to absorb the energy. The difference in values of plastic impact strength (toughness) between plastic types, which was the ability to absorb energy during plastic deformation, is considered a key factor. The toughness value of PET is $15.25 \mathrm{~J} / \mathrm{cm}$ while they are $5.58 \mathrm{~J} / \mathrm{cm}$ and $0.685 \mathrm{~J} / \mathrm{cm}$ for HDPE and PP, respectively [26-28]. Therefore, as indicated in Figure 3, R5 and R6 only had HDPE and PP, showed least impact strength improvement.

Figure 4 shows that the failure patterns of MRPC were irregular in all specimens, and in most specimens, they were not confined between the two notches as in the control mix. Specimens with $20 \%$ and $30 \%$ replacement ratios showed more cracks which meant better impact loads distribution. Discs failure patterns were similar to that described by Mohammadhosseini, Tahir and Sam [29], who used metalized plastic fibre. During the test, the stresses were better transmitted within the concrete matrix due to the crack-capturing influence of the plastic. The plastic aggregates bound the cracks together post peak load. 

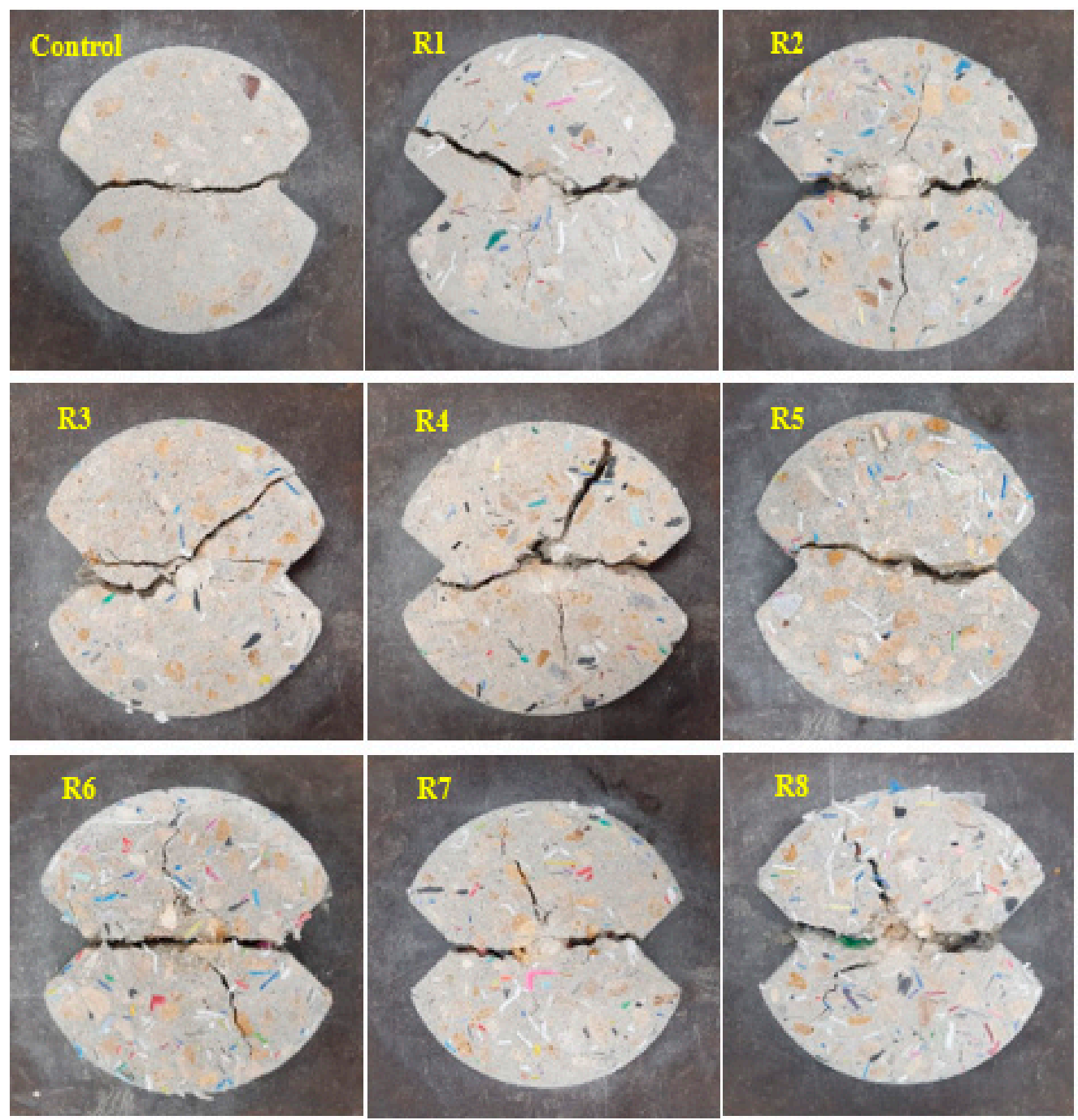

Figure 4. Failure patterns of the MRPC specimens.

Figure 5 illustrates the relationship between the compressive strength and impact energy calculated by Equation (4). An inverse relation was observed between the compressive strength (for the same mixes from a previous study [13]) and the impact energy, and a strong correlation was achieved with the coefficient of determination of more than 0.96 (Figure 5). This improvement in impact resistance response may make MRPC a suitable choice for engineering applications with high impact requirements such as crash barriers.

$$
\text { Impact energy }=\mathrm{N} \times \mathrm{m} \times \mathrm{g} \times \mathrm{h}
$$

$\mathrm{N}=$ Number of blows for final failure of specimen

$\mathrm{m}=$ Mass of steel cylinder $(4.5 \mathrm{~kg})$

$\mathrm{g}=$ Gravity acceleration $\left(9.81 \mathrm{~m} / \mathrm{s}^{2}\right)$

$\mathrm{h}=$ Drop distance $(200 \mathrm{~mm})$.

\subsection{Water Transport Properties}

\subsubsection{Water Absorption}

Figure 6 presents the water absorption results for all mixes. It was found that the values tended to increase slightly with increasing plastic replacement ratios in all mixes, however R1 and R3 showed values slightly less than the control mix. Comparing between the mixes that contain the same replacement ratio revealed that R1 and R3 had water 
absorption values less than R5. This was attributed to the presence of PET plastic type in R1 and R3. The SEM micrograph of concrete mixed with PET revealed a stronger bonding that decreased the formation of air voids at the interfacial transition zone comparing with the other two types (HDPE and PP) [2]. The same observation was recorded for the mixes that contained higher replacement ratio; the water absorption for R2 and R4 were lower than R6. This is also supported by comparing the values of water absorption for R7 and R8 (which contain PET) with R5 and R6 (without PET) which showed lower values, although $\mathrm{R} 8 \mathrm{had}$ the highest replacement ratio of $30 \%$. It is worth mentioning that the highest increase in water absorption value was achieved by R6 mix. This could be due to higher air content value of the same mix in a previous study of the same authors [13]. However, the current findings are not consistent with the results of [7], who reported a reduction in water absorption in concrete included mixed plastic types despite the difference in experimental details. They attributed the results to the effect of using air-reducing surfactant which affected the hydrophobic nature of the polymer flakes.

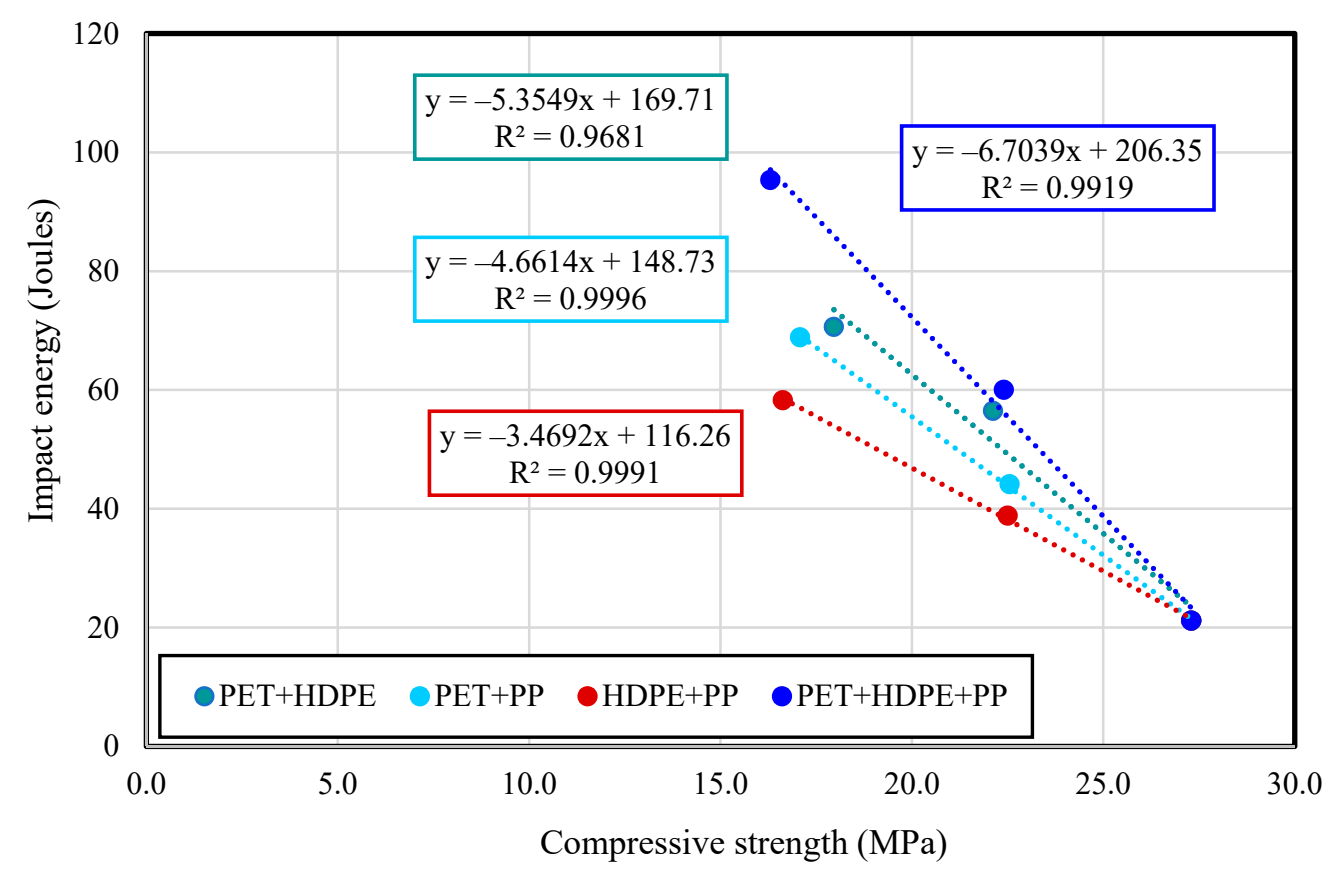

Figure 5. The relation between the compressive strength and the impact energy.

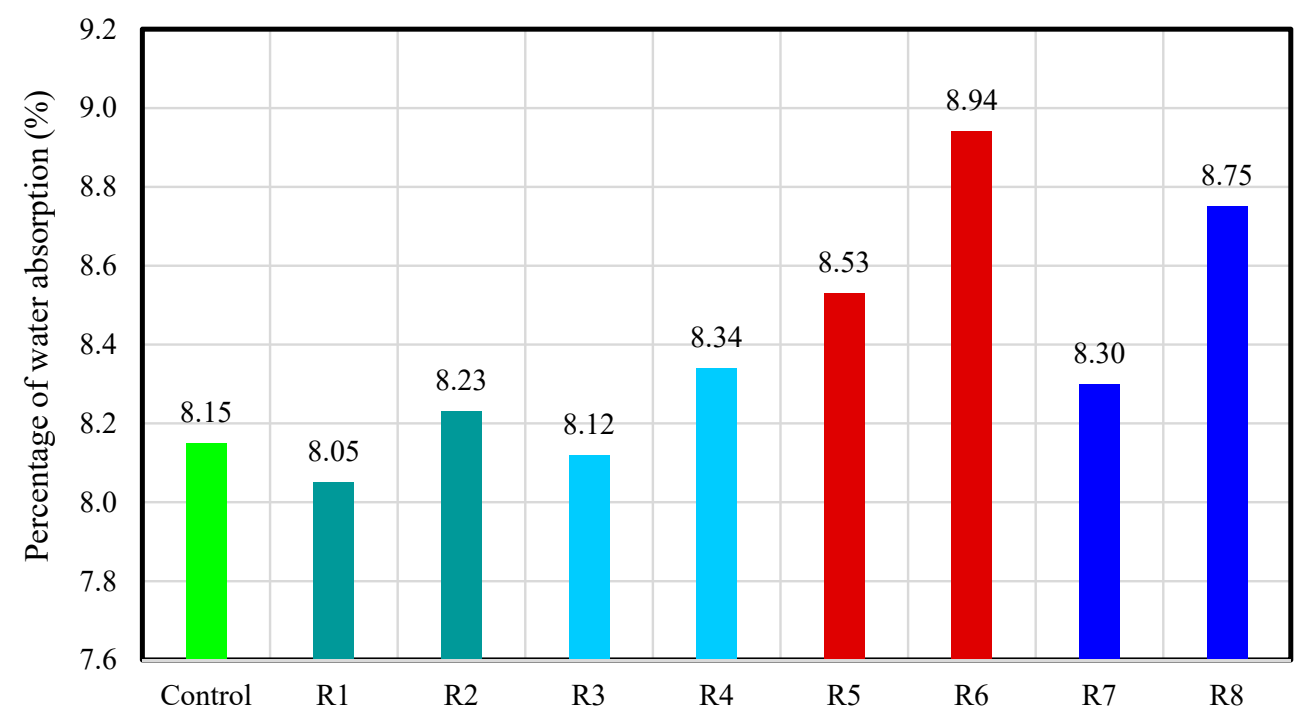

Figure 6. Percentage of water absorption for different replacement ratios. 


\subsubsection{Water Sorptivity}

It is well known that sorptivity is related closely to the tendency of concrete material absorbing liquids through capillary pressures and a good concrete quality is represented by low values of sorptivity. Water can carry dissolved sulphate ions through the concrete, as such water sorptivity can provide reliable information about concrete degradation due to sulphate attack [30]. Figure 7 illustrates the capillary water absorption $(\mathrm{mm})$ vs. time $(\sqrt{s})$ for all mixes. The analysis of results revealed inconsistent disparities in the behaviour of different specimens. Figures 8 and 9 represent the sorptivity coefficient (initial and secondary rate of absorption) of capillary water absorption curves with time. The first four mixes (R1 to R4) exhibited a clear increase in the initial rate of absorption with a maximum increase of $26.7 \%$ compared to the control mix. R6 shows a decrease of $2.2 \%$, while R8 was equal to the control mix. Inspecting the secondary rate of absorption values revealed that $\mathrm{R} 1$ to $\mathrm{R} 3$ achieved the same values despite the variation in plastic types and the replacement ratios. The similarity in the behaviour among R5, R6 and R8 on one hand and R4 and R7, on the other hand, meant that increasing the number of plastic types to three and the replacement ratio up to $15 \%$ or even to $30 \%$ did not change the sorptivity to a detrimental level. The obtained outcomes of this study were not in agreement with [8], who reported a decrease in the sorptivity values when using unknown mixed plastic up to $30 \%$. For replacement more than $30 \%$, the values increased. When more plastic was used, more tiny air bubbles were entrapped by the small sized flaky plastic aggregates that increased the pore size and as a result water sorptivity increased. Differences in plastic types, the filling effect and variations in hydrophobicity of plastic aggregates to water were among the factors responsible for the resultant values.

The relatively large size and flake shape of the coarse plastic aggregate might help to create capillary pores within the concrete that allowed the water to move more freely. It is well established that the movement of the water within the concrete is affected by different factors, including the pore size and shape, inter-connectedness of the pores and the surface tension of liquids [31]. Smaller, interconnected pores help the capillary water column to rise up higher. In general, plastic has lower surface energy compared to other materials, (i.e., coarse and fine aggregates), in addition to the differences between them. Higher surface energy of plastic type assisted in the continuity of the water column during the capillary action since water has more adherence to the walls surface inside the concrete matrix. PET has higher surface energy compared to the other two plastic types, HDPE and PP, but the resultant value has been overlooked because of mixing with other types. The variation in surface energy values among different types of plastic depends on their chemical composition, which affects the molecular force of attraction.

\subsection{Resistance to Sodium Sulphate Attack}

Generally, sulphate attack occurs when sulphate ions, which are mainly present in water, penetrate into the concrete, where they interact with the cement paste components to form minerals that lead to the expansion of concrete. Concrete resistance to sulphate attack is an important parameter in judging durability since vulnerable concrete to sulphate attack suffers from internal expansion and deterioration [11].

\subsubsection{Visual Inspection}

During testing, visual inspection of the cylinders showed no residue of deterioration before 80 wet-dry cycles. After 90 wet-dry cycles, Figure 10 reveals the dissolving of the exterior cement paste layer of the tested mixes. In both MRPC mixes (R7 and R8), parts of the plastic aggregates were exposed as a result of corners deterioration. R8, with its higher plastic replacement content $(30 \%)$ showed more corner deterioration and visible cracks compared to R7 (15\%). No expansion or spalling was noticed at the end of the test. 

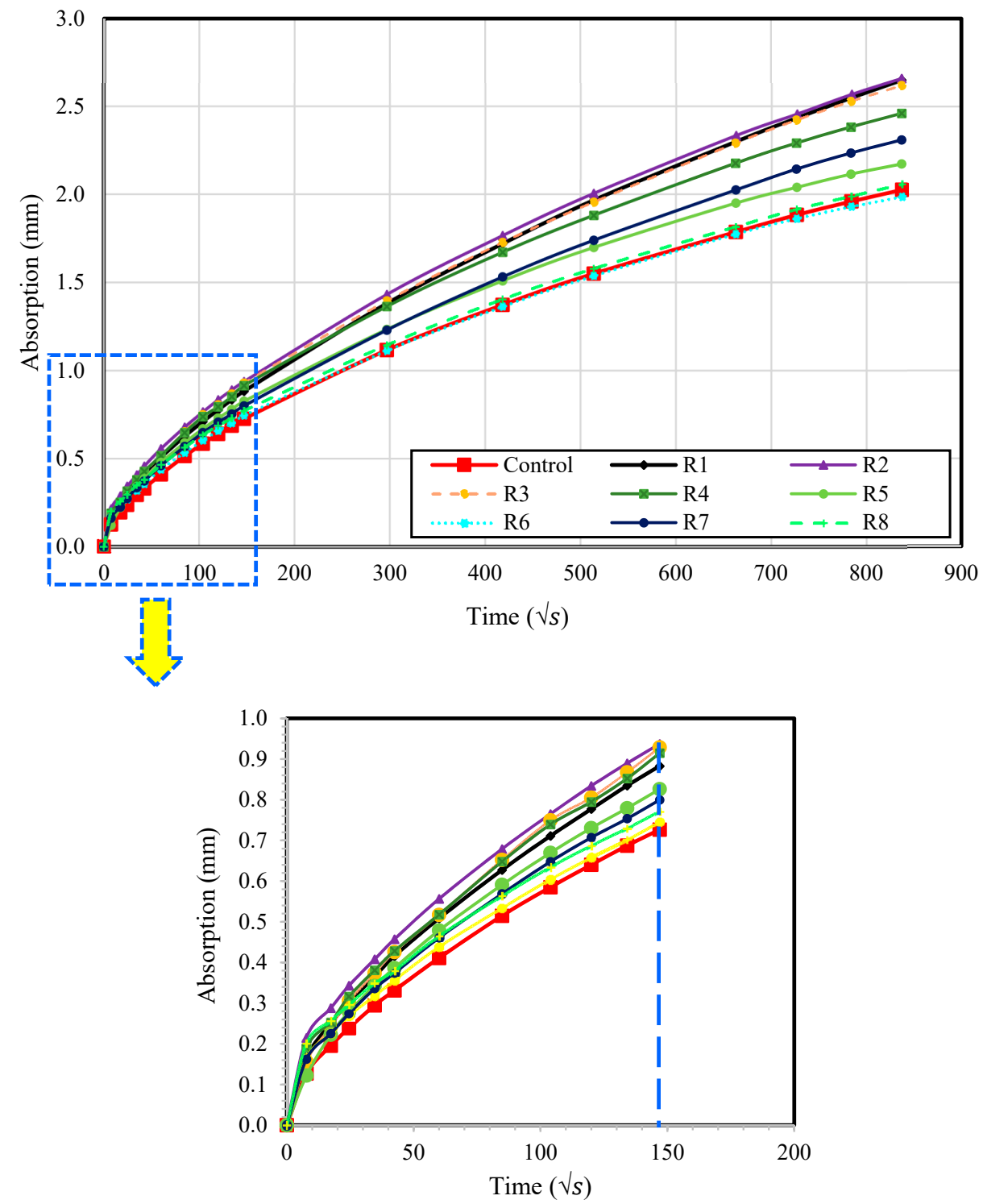

Figure 7. The water absorption vs. time for all mixes.

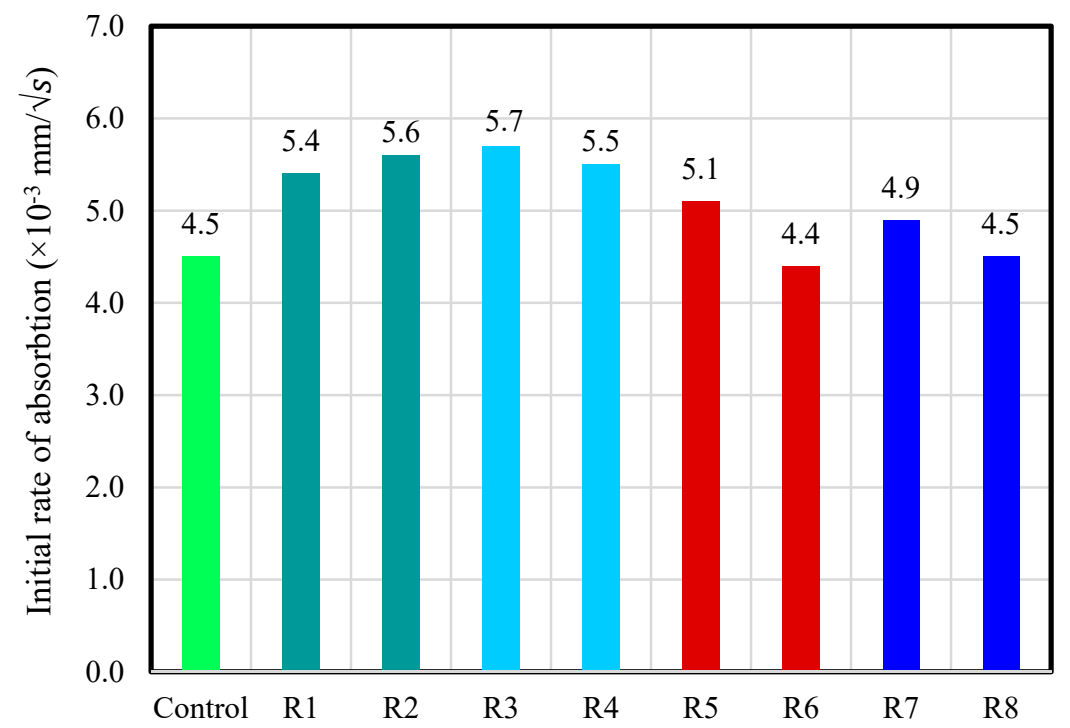

Figure 8. Initial rate of absorption. 


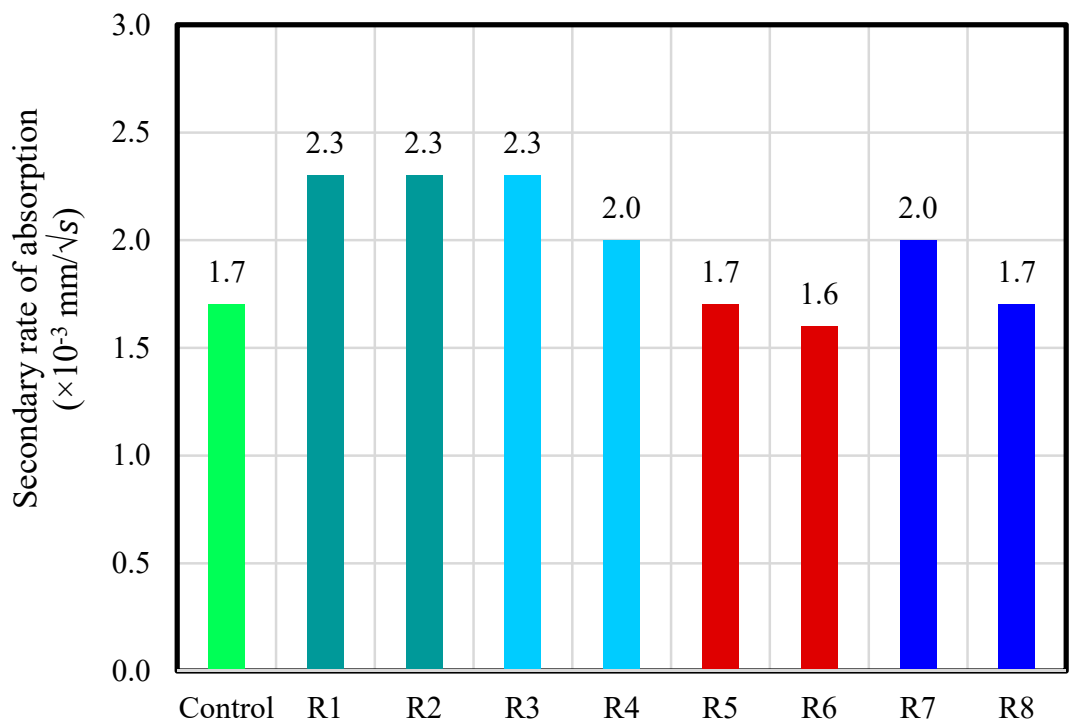

Figure 9. Secondary rate of absorption.

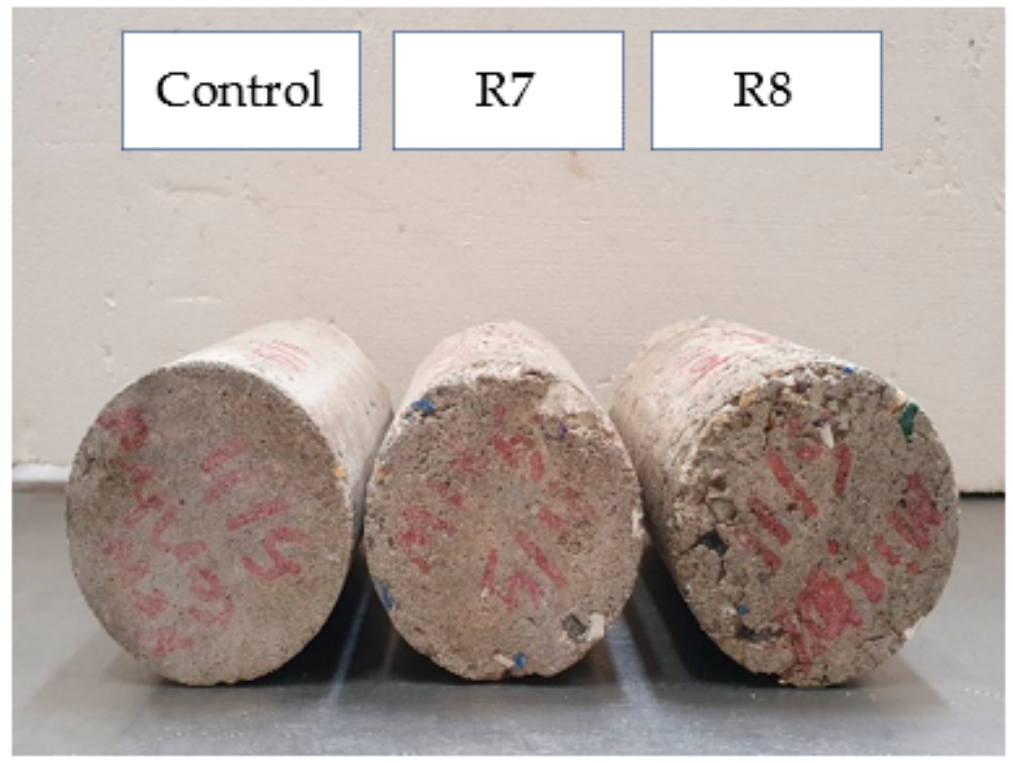

Figure 10. Signs of surface material loss after 90 wet-dry cycles.

\subsubsection{Mass Change}

As mentioned previously, the sodium sulphate attack for the selected mixes (R7, R8 and the control) was measured by immersion the samples in sodium sulphate solution for 90 wet-dry cycles. The mass of mixes related to the number of cycles are illustrated in Figure 11. As shown, a decrease in the masses was observed during the first cycle due to water evaporation after the beginning of the drying process. However, it has a negligible effect on the rest of the readings. A similar case was reported by other researchers [32]. After that, the specimens experienced comparable behaviour and gained more mass due to composition of higher quantities of gypsum, ettringite or other sulphate minerals that filled the pores. Mass gain as a result of the formation of the previously mentioned corrosion products has been reported by Benosman et al. [12]. Moreover, the control mix continued to follow the same behaviour until the end of the test. Such behaviour was inconsistent with that reported by Li et al. [33], the mass loss only initiated after around 120 cycles. By calculating the percentage of increase of the mass of mixes between 10-80 cycles, the results showed that the mass gain was higher in R8 mix compared to the control and R7 mixes. 
A possible reason for this result might be the increased sequestration of sulphate ions in the pore spaces between the plastic aggregates and cement paste after penetration. After 83 cycles, the mass of R8 started to decrease gradually. R7 followed the similar trend after a few cycles, but the drop was insignificant. As mentioned, none of the previous studies investigated the sodium sulphate attack for MRPC. However, and despite the variation in the testing method, Lakshmi and Nagan [34] showed a loss of weight after 105 days for samples of concrete incorporating $12 \%$ E-plastic waste. The results showed that the loss of weight for E-plastic concrete mixes was less than the control mix.

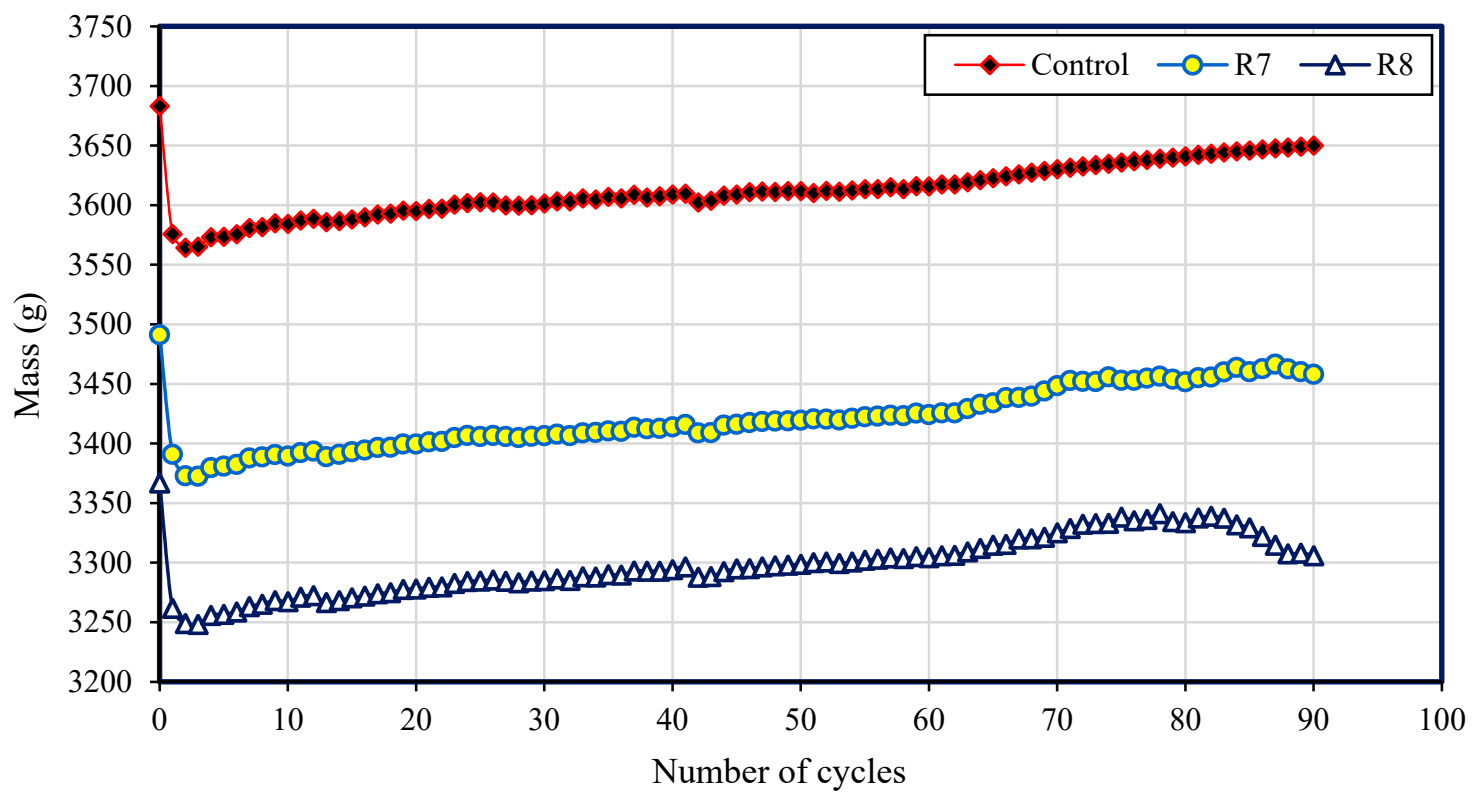

Figure 11. The mass of the tested mixes related to the number of cycles.

\subsubsection{Compressive and Splitting Tensile Strengths}

Figure 12 shows the compressive strength of the tested mixes before [13] and after the sodium attack test. As expected, the results revealed a decrease in the strength by $9.2 \%, 14.9 \%$ and $20.7 \%$ for the control, R7 and R8, respectively. This can be attributed to the increased content of the mixed recycled plastic ratio in R8. This led to an increase in sodium sulphate infiltration as a result of air void and porous internal structure and consequently the formation of more minerals which adversely affected the compressive strength. Figure 13 shows the values of splitting tensile strength before [13] and after the sodium attack test. This showed that they followed the same trend as compressive strength with a decrease of $6.9 \%, 27.6 \%$ and $17 \%$ for the control, R7 and R8, respectively. This indicates that the loss in both compressive and splitting tensile strengths was higher in MRPC mixes compared to the control. Among limited studies, Benosman et al. [12] studied the compressive and flexural strengths of concrete composites contained PET recycled plastic after exposure to 180 days sodium sulphate attack. The findings showed an increase in compressive strength for mixes with higher plastic content although all values were less than the control mix. They attributed the reason to the impervious nature of PET granules that blocked the passage of sodium sulphate solution. In addition, they reported an inconsistent result for flexural strength values. 


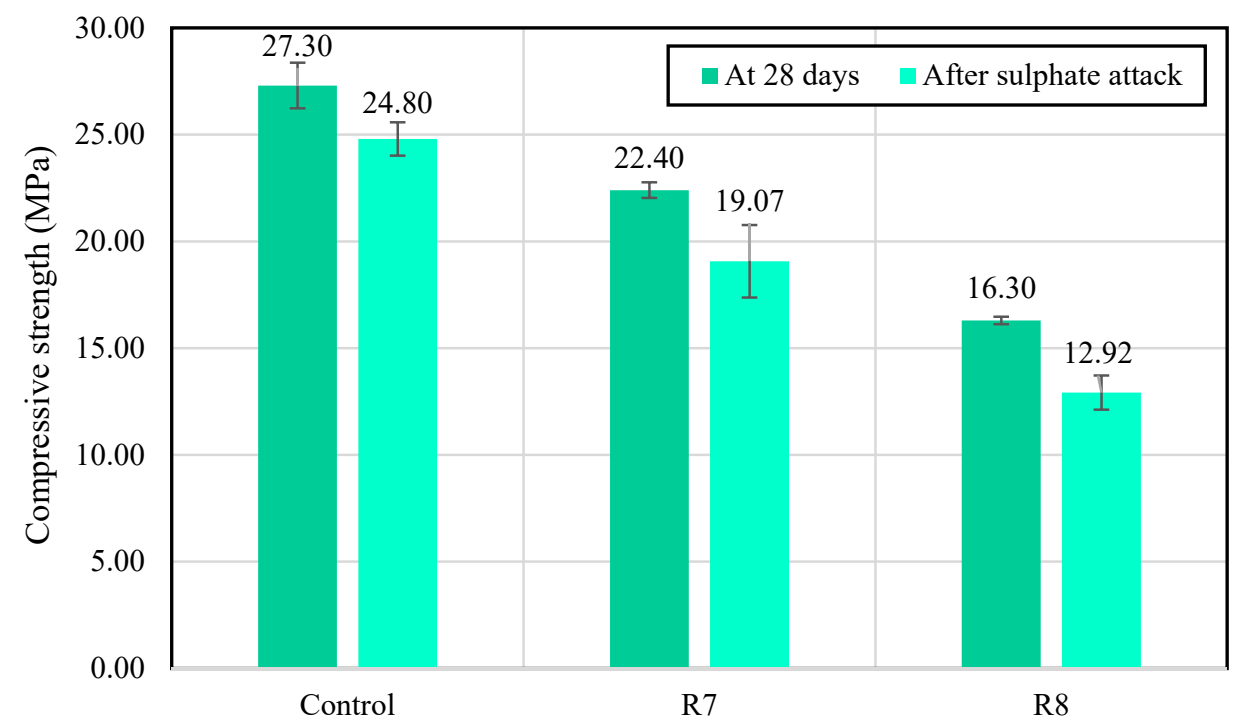

Figure 12. The compressive strength of the tested mixes before and after sulphate attack.

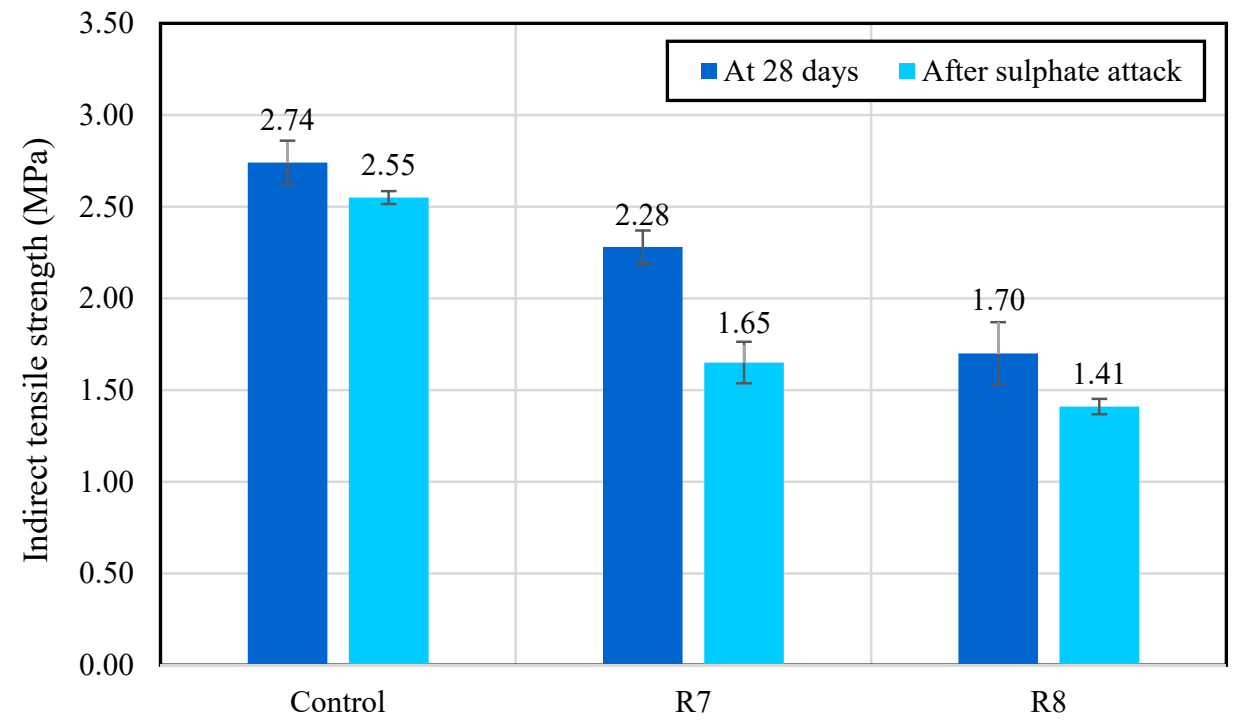

Figure 13. The splitting tensile strength of the tested mixes before and after sulphate attack.

\subsubsection{SEM Images and EDS Analysis}

Figures 14-16 illustrate SEM micrographs of the concrete fractures of the three mixes (control, R7 and R8) that subjected to 90 wet-dry cycles of sodium sulphate attack. Also, they showed the EDS elements analysis at the marked spot of the same mixes. The SEM figures revealed the presence of various minerals. Figure 14a which represents the control mix, showed an extensive amount of cubic-shaped crystals. The EDS spectra indicated the presence of calcium, sulphur, carbon and oxygen which confirmed the presence of gypsum/anhydrite and calcite. The flower-shaped mineral shown in Figure 14b can be considered an advanced stage of gypsum formation while the white micro rods was suggested to be aragonite. The presence of two minerals was confirmed by EDS analysis (Figure 14a,b). Moreover, SEM images of R7 mix (15\% replacement with three mixed types of recycled plastic) showed different shaped crystals compared to the control mix (Figure 15a,b). The mesh-shaped structure which formed on the cement paste constituent is thenardite corrosion mineral (Figure 15a). The sodium sulphate solution was absorbed by the concrete and filled the pores and air voids before it crystallized as a result of wet-dry cycles. This was further confirmed by EDS spectrum that included high amount of sodium. 


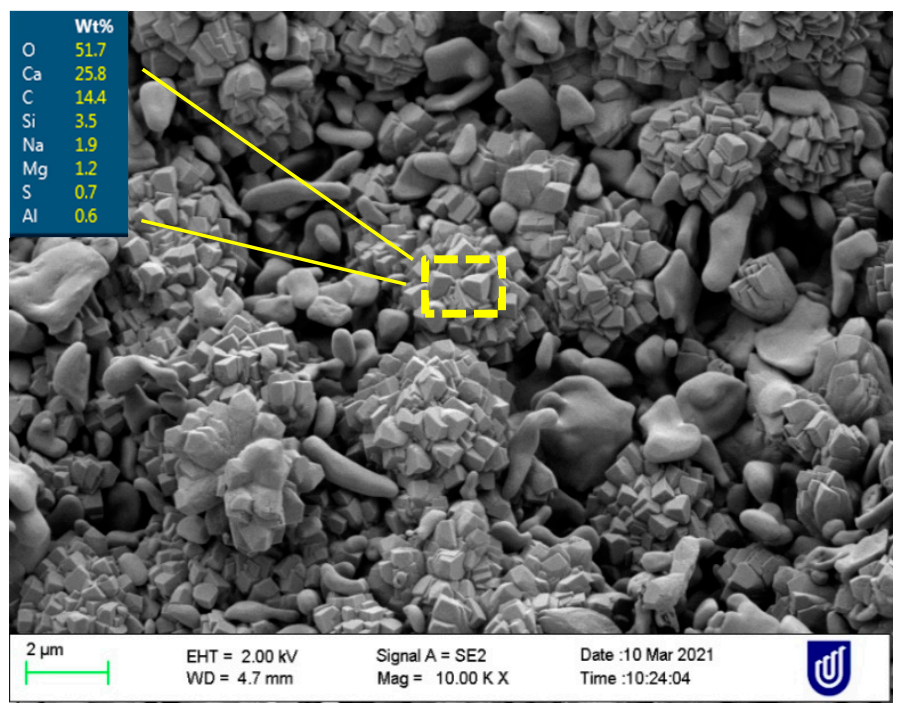

(a)

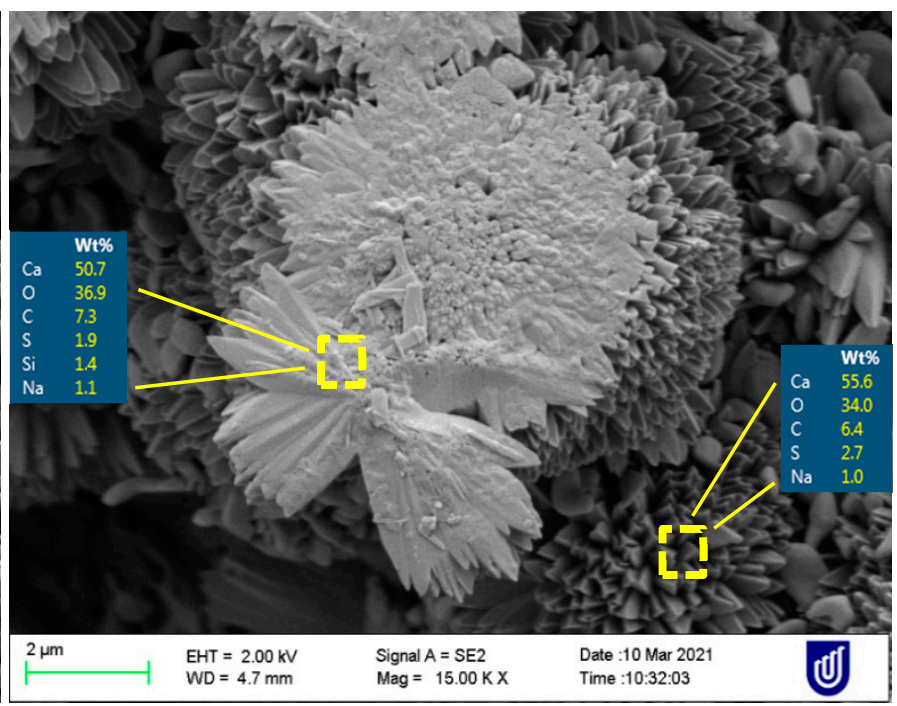

(b)

Figure 14. Crystallizations and EDS analysis for the control mix (a) gypsum/anhydrite and calcite (b) gypsum and aragonite.

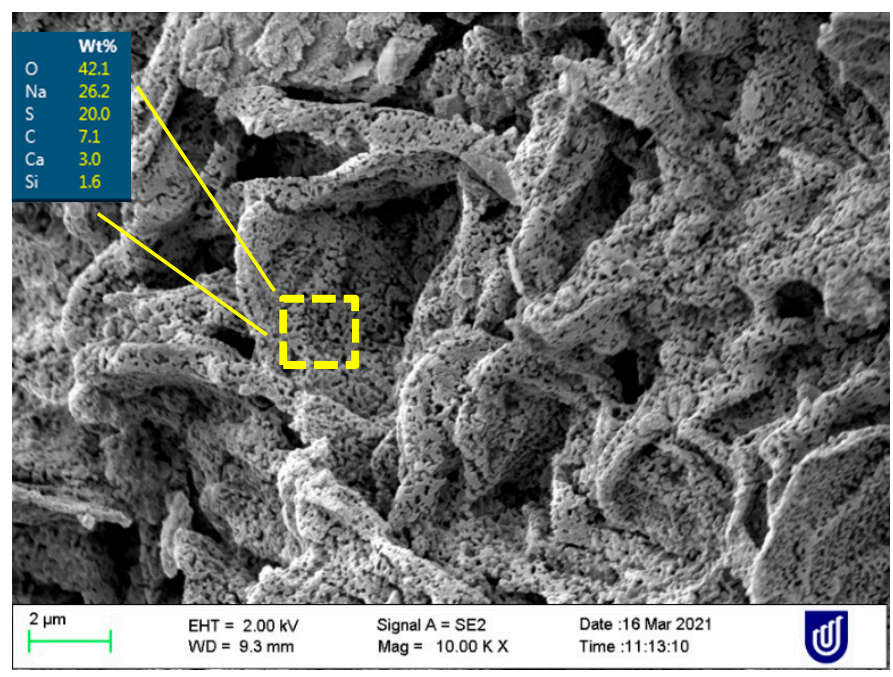

(a)

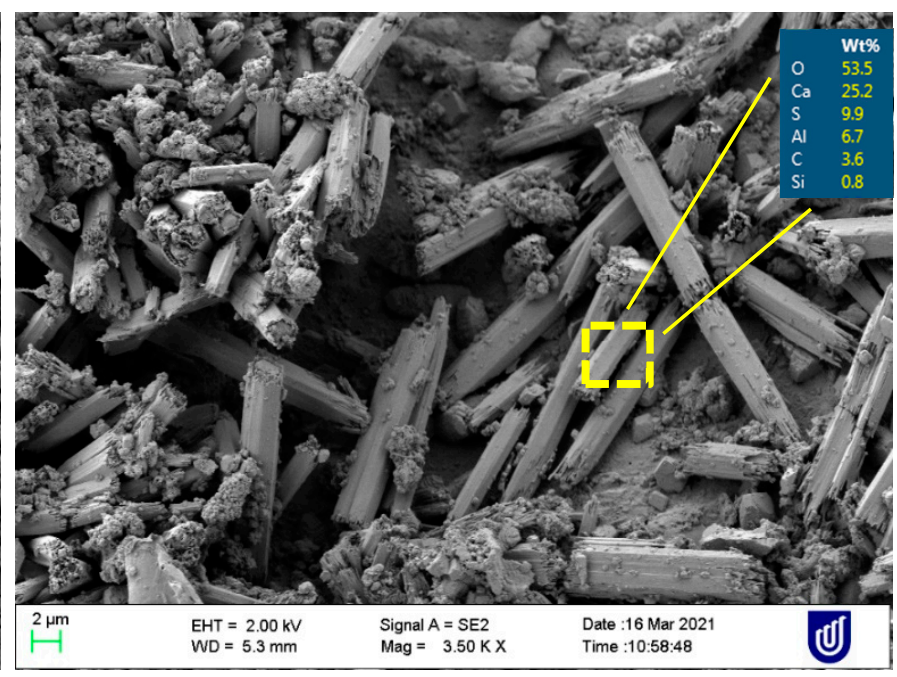

(b)

Figure 15. Crystallizations and EDS analysis for R7 mix (a) thenardite (b) ettringite.

Abundant stick-shaped crystallization was found in Figure 15b. Based on the EDS analysis which indicated the presence of aluminium, sulphur and calcium, it is suggested to be ettringite. High crystal growth was noticed in SEM images of R8 in comparison to control and R7 mixes. Entangled stick-like structures (Figure 16a), flower-like shapes with thin needles (Figure 16b) and rosette-like sheets with transverse intersections (Figure 16c) were embedded in the microstructure of the concrete. By using the analysis of the EDS spectra, the previous mentioned shapes were suggested to be ettringite, aragonite and brucite, respectively, as the EDS element analysis indicated (Figure 16a-c).

It was reported that the effect of sulphate attack process was greater in concrete contains higher plastic proportions due to higher air void and porosity at the ITZ interfaces which allowed the sulphate ions to enter and react freely [12]. However, the appearance of ettringite may be delayed due to its decomposition at low $\mathrm{pH}$ values (less than 10.7) caused by the presence of organic materials that contaminate the plastic [35]. 


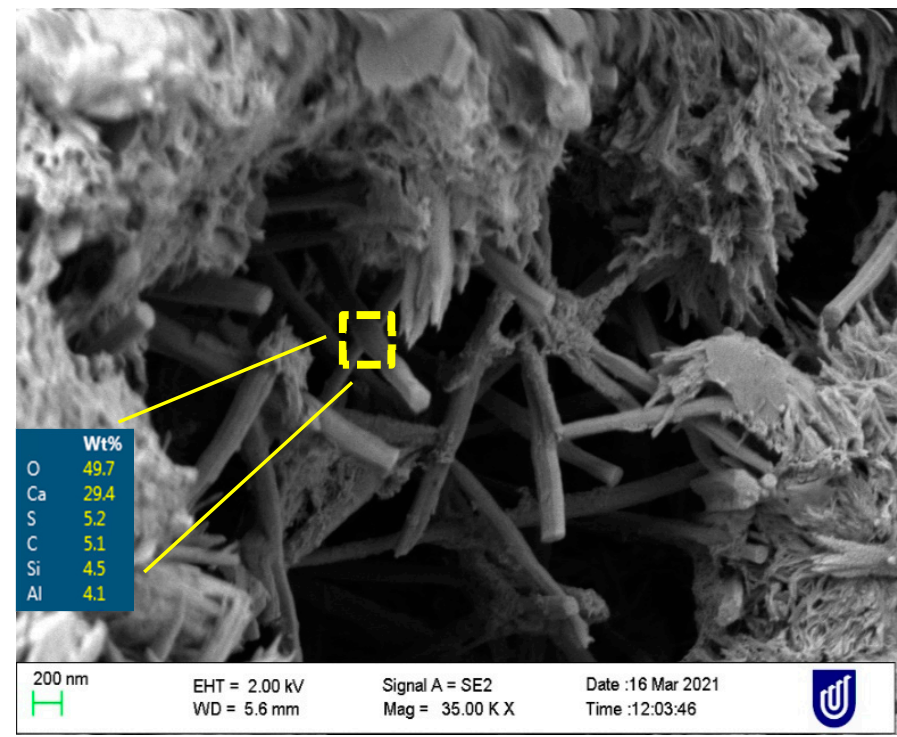

(a)

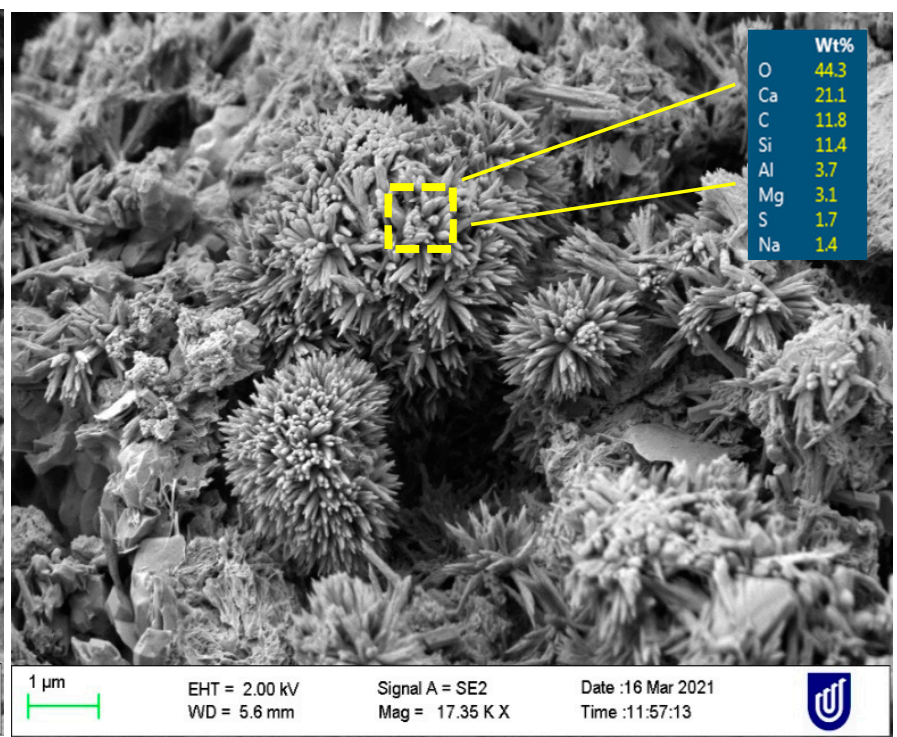

(b)

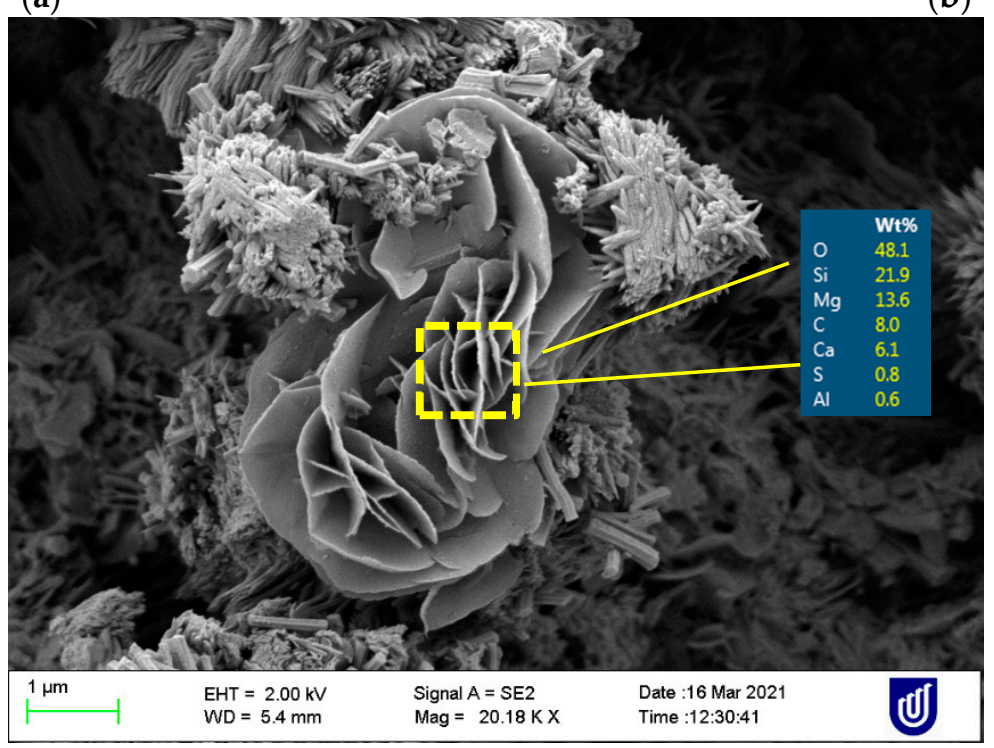

(c)

Figure 16. Crystallizations and EDS analysis for R8 mix (a) ettringite (b) aragonite (c) brucite.

\section{Conclusions}

In this study, the impact resistance, water transport properties and sodium sulphate attack resistance of concrete incorporated with mixed types of recycled plastic aggregate were evaluated. The following conclusions are drawn from the results:

1. The addition of mixed types recycled plastic in concrete improved the impact resistance for all mixes. The presence of PET effectively improved the quality of concrete by increasing the number of blows to cause the failure of the samples;

2. The addition of PET plastic in the concrete containing MRPC tended to decrease the water absorption values more than the other two types. This is attributed to the stronger bond of PET with concrete paste compared with other two types;

3. In terms of sorptivity results, it is better to add PET plastic type with the two other types to overlook the surface energy property of PET towards water;

4. Analysis of mass change showed that the incorporation of higher plastic content negatively affected sodium sulphate resistance slightly as a result of sulphate ion deposition within the pores and voids during the test period; 
5. In general, the compressive and splitting tensile strengths of the tested MRPC decreased slightly after 90 wet-dry cycles of sodium sulphate exposure;

6. The microstructural analysis detected that the mixes including recycled plastic waste have more corrosion minerals with different forms compared to the control mix.

Further research is required to verify the durability performance of concrete containing other mixed types of plastic. In addition, a field trial on kerb, footpath or residential road is recommended based on the results of this study to understand the performance of concrete incorporating mixed plastic under a long period of time with ambient weather and real loading conditions. The transition to a more sustainable solution for plastic waste materials requires an urgent collaboration of all stakeholders to assist the government in waste management, maximising all possible opportunities. This research could provide essential information for the construction sector, especially local councils to direct the future efforts in enhancing concrete performance to guarantee concrete with acceptable durability properties.

Author Contributions: M.A.-S.: Data curation, Formal analysis, Investigation, Methodology, Validation, Writing-original draft. Y.Z.: Conceptualization, Methodology, Project administration, Supervision, Writing — review and editing. R.H.: Supervision, Writing-review and editing. M.E.: Methodology, Supervision, Writing—review and editing. M.M.R.: Supervision, Writing-review and editing. P.L.: Conceptualization, Supervision, Writing-review and editing. All authors have read and agreed to the published version of the manuscript.

Funding: This research received no external funding.

Institutional Review Board Statement: Not applicable.

Informed Consent Statement: Not applicable.

Data Availability Statement: The data presented in this study are available on request from the corresponding author.

Acknowledgments: The authors would like to acknowledge the University of South Australia for providing laboratory support, City of Salisbury for support and RPA Recycling Plastics Australia Pty Ltd., (Kilburn, Australia) for plastics supply. The authors also acknowledge the contributions of Honours' student, Gabriel McKenna-Lieschke who assisted in the water absorption experimental work reported in this paper. Thanks are also due to Adelaide Brighton Cement Pty. Ltd., (Angaston, Australia) for supplying cement and Master Builders Solutions (BASF) for providing superplasticizer.

Conflicts of Interest: The authors declare no conflict of interest.

\section{References}

1. The Australian Government, State and Territory Governments, The Australian Local Government Association. National Waste Policy Action Plan 2019. Available online: https://www.environment.gov.au/protection/waste/publications/national-wastepolicy-action-plan (accessed on 2 January 2021).

2. Abu-Saleem, M.; Zhuge, Y.; Hassanli, R.; Ellis, M.; Rahman, M.; Levett, P. Evaluation of concrete performance with different types of recycled plastic waste for kerb application. Constr. Build. Mater. 2021, 293, 123477. [CrossRef]

3. Olofinnade, O.; Chandra, S.; Chakraborty, P. Recycling of high impact polystyrene and low-density polyethylene plastic wastes in lightweight based concrete for sustainable construction. Mater. Today Proc. 2021, 38, 2151-2156. [CrossRef]

4. Villanueva, A.; Eder, P. End-of-Waste Criteria for Waste Plastic for Conversion; European Commission: Luxembourg, 2014.

5. Harper, C.A.; Petrie, E.M. Plastics Materials and Processes: A Concise Encyclopedia; John Wiley \& Sons, Inc.: Hoboken, NJ, USA, 2003.

6. Chanda, M. Plastics Technology Handbook, 5th ed.; CRC Press, Taylor \& Francis: Boca Raton, FL, USA, 2018.

7. Jacob-Vaillancourt, C.; Sorelli, L. Characterization of concrete composites with recycled plastic aggregates from postconsumer material streams. Constr. Build. Mater. 2018, 182, 561-572. [CrossRef]

8. Mohammadinia, A.; Wong, Y.C.; Arulrajah, A.; Horpibulsuk, S. Strength evaluation of utilizing recycled plastic waste and recycled crushed glass in concrete footpaths. Constr. Build. Mater. 2019, 197, 489-496. [CrossRef]

9. Saxena, R.; Siddique, S.; Gupta, T.; Sharma, R.K.; Chaudhary, S. Impact resistance and energy absorption capacity of concrete containing plastic waste. Constr. Build. Mater. 2018, 176, 415-421. [CrossRef]

10. Jain, A.; Siddique, S.; Gupta, T.; Sharma, R.K.; Chaudhary, S. Utilization of shredded waste plastic bags to improve impact and abrasion resistance of concrete. Environ. Dev. Sustain. 2020, 22, 337-362. [CrossRef]

11. Sancak, E.; Özkan, Ş. Sodium sulphate effect on cement produced with building stone waste. J. Mater. 2015, 2015, 12. [CrossRef] 
12. Benosman, A.; Taïbi, H.; Senhadji, Y.; Mouli, M.; Belbachir, M.; Bahlouli, M. Plastic waste particles in mortar composites: Sulfate resistance and thermal coefficients. Prog. Rubber Plast. Recycl. Technol. 2017, 33, 171-202. [CrossRef]

13. Abu-Saleem, M.; Zhuge, Y.; Hassanli, R.; Ellis, M.; Rahman, M.M.; Levett, P. Stress-Strain Behaviour and Mechanical Strengths of Concrete Incorporating Mixed Recycled Plastics. J. Compos. Sci. 2021, 5, 146. [CrossRef]

14. Standards Australia. Methods for Sampling and Testing Aggregates-Particle Density and Water Absorption of Coarse Aggregate-Weighingin-Water Method, AS1141.6.1; Standards Australia Limited: Sydney, Australia, 2000.

15. Standards Australia. Methods for Sampling and Testing Aggregates-Particle Density and Water Absorption of Fine Aggregate, AS 1141.5; Standards Australia Limited: Sydney, Australia, 2000.

16. ASTM D792. Standard Test Methods for Density and Specific Gravity (Relative Density) of Plastics by Displacement; ASTM International: West Conshohocken, PA, USA, 2013.

17. Standards Australia. Methods for Sampling and Testing Aggregates, Method 11.1: Particle Size Distribution-Sieving Method, AS 1141.11.1; Standards Australia Limited: Sydney, Australia, 2009.

18. Standards Australia. Methods of Testing Concrete, Preparation of Concrete Mixes in the Laboratory, AS 1012.2; Standards Australia Limited: Sydney, Australia, 2014.

19. Standards Australia. Methods of Testing Concrete, Method for Making and Curing Concrete—Compression and Indirect Tensile Test Specimens, AS 1012.8.1; Standards Australia Limited: Sydney, Australia, 2014.

20. Shah, S.P.; Daniel, J.I.; Ahmad, S.H.; Arockiasamy, M.; Balaguru, P.; Ball, C.G.; Ball, H.P.; Batson, G.B.; Bentur, A.; Craig, R.J. Measurement of properties of fiber reinforced concrete. ACI Mater. J. 1988, 85, 583-593.

21. Badr, A.; Ashour, A.F. Modified ACI Drop-Weight Impact Test for Concrete. ACI Mater. J. 2005, 102, $249-255$.

22. Standards Australia. Methods of Testing Concrete-Determination of Water Absorption and Apparent Volume of Permeable Voids in Hardened Concrete, AS 1012.21; Standards Australia Limited: Sydney, Australia, 1999.

23. ASTM C1585. Standard Test Methods for Measurement of Rate of Absorption of Water by Hydraulic Cement Concretes; ASTM International: West Conshohocken, PA, USA, 2013.

24. Standards Australia/Standards New Zealand. Masonry Units and Segmental Pavers and Flags-Methods of Test-Method 10: Determining Resistance to Salt Attack, AS/NZS 4456.10; Standards Australia Limited: Sydney, Australia; Standards New Zealand: Wellington, New Zealand, 2003.

25. Mohammadhosseini, H.; Tahir, M.M. Durability performance of concrete incorporating waste metalized plastic fibres and palm oil fuel ash. Constr. Build. Mater. 2018, 180, 92-102. [CrossRef]

26. DesignerData. Impact Strength of Polyethylene Terephthalate. Available online: https://designerdata.nl/materials/plastics/ thermo-plastics / polyethylene-terephthalate (accessed on 2 January 2021).

27. DesignerData. Impact Strength of High Density Polyetheen. Available online: https://designerdata.nl/materials/plastics/ thermo-plastics/high-density-polyetheen (accessed on 2 January 2021).

28. DesignerData Impact Strength of Polypropylene. Available online: https://designerdata.nl/materials/plastics/thermo-plastics/ polypropylene-(cop.) (accessed on 2 January 2021).

29. Mohammadhosseini, H.; Tahir, M.M.; Sam, A.R.M. The feasibility of improving impact resistance and strength properties of sustainable concrete composites by adding waste metalized plastic fibres. Constr. Build. Mater. 2018, 169, 223-236. [CrossRef]

30. Skalny, J.P.; Marchand, J.; Odler, I. Sulfate Attack on Concrete; Spon Press: London, UK, 2002; pp. 43-126.

31. Shah, R.A.; Pitroda, J. Effect of water absorption and sorptivity on durability of pozzocrete mortar. Int. J. Emerg. Sci. Eng. 2013, 1, 73-77.

32. Guo, X.; Xiong, G. Resistance of fiber-reinforced fly ash-steel slag based geopolymer mortar to sulfate attack and drying-wetting cycles. Constr. Build. Mater. 2021, 269, 121326. [CrossRef]

33. Li, Q.; Li, X.; Yang, K.; Zhu, X.; Gevaudan, J.P.; Yang, C.; Basheer, M. The long-term failure mechanisms of alkali-activated slag mortar exposed to wet-dry cycles of sodium sulphate. Cem. Concr. Compos. 2021, 116, 103893. [CrossRef]

34. Lakshmi, R.; Nagan, S. Investigations on durability characteristics of E-plastic waste incorporated concrete. Asian J. Civ. Eng. 2011, 12, 773-787.

35. Gabrisova, A.; Havlica, J.; Sahu, S. Stability of calcium sulphoaluminate hydrates in water solutions with various $\mathrm{pH}$ values. Cem. Concr. Res. 1991, 21, 1023-1027. [CrossRef] 